\title{
EVALUATION OF THE INFLUENCE OF WIND-DRIVEN RAIN ON MOISTURE IN CELLULAR CONCRETE WALL BOARDS
}

\author{
A. ALSABRY* \\ University of Zielona Góra \\ Faculty of Civil Engineering, Architecture and Environmental Engineering \\ Str. Licealna 9, 65-417 Zielona Góra, POLAND \\ E-mail: aalsabry@uz.zgora.pl \\ V.I. NIKITSIN \\ Pope John Paul II State School of Higher Education in Biala Podlaska \\ 95/97 Sidorska Str. Biala Podlaska 21-500, POLAND \\ V.A. KOFANOV \\ Brest State Technical University \\ 267 Moskovskaya Str. Brest 224017, BELARUS \\ B. BACKIEL-BRZOZOWSKA \\ Białystok University of Technology \\ 45E Wiejska Str. Bialystok 15-351, POLAND
}

\begin{abstract}
The non-stationary moisture level of a cellular concrete wall board in a heated utility building located in the northern part of the town of Brest (Belarus), depending on the climatic influence, was assessed in this work. The results were obtained both in a calculation experiment and a physical test. It was observed that the main reason for the high moisture levels in cellular concrete is wind-driven rain intensifying the process of free capillary moisture transfer. A comparative analysis of the results of the physical test and the calculation experiment showed that the THSS software elaborated by the authors was able to predict the actual moisture levels of the shielding structure under study accurately enough when precise data concerning the thermal and physical characteristics of the materials as well as the occurring climatic influences were submitted.
\end{abstract}

Key words: cellular concrete, wind-driven rain, capillary transfer, water sorption coefficient, moisture content.

\section{Introduction}

The durability of external walls and the heat-moisture processes occurring in them strongly depend on the external climate, i.e., the temperature, rainfall, wind speed and direction, relative air moisture and insolation, as well as on how fast they change.

One of the main causes of moisture in external walls is so called wind-driven rain [1-3].

Results of numerous physical tests conducted in the last decades indicate that the moisture content for capillary-porous materials in building enclosures usually exceeds the moisture values adopted while designing these structures. Increased moisture levels reduce their heat-preserving characteristics and bring about some other widely known negative results [4]. Therefore, moisture content for shielding materials must be forecasted accurately enough, with the use of appropriate calculation methods, as early as in the building design phase.

A number of publications (e.g. $[5,6,7,8,9,10])$ underline that one of the main reasons of increased moisture levels in shielding structures is exposure of the external surfaces to atmospheric precipitation and

\footnotetext{
* To whom correspondence should be addressed
} 
wind at the same time, a phenomenon called wind-driven rain. Depending on the intensity and duration of wind-driven rain, and also on the capillary characteristics of materials, the amount of rain moisture falling on the shielding structure surfaces is completely or partially absorbed by the surface layers of their materials, and, owing to the capillary moisture transfer, this amount increases the moisture content of the shielding structure relatively fast and to a considerable extent.

In the present paper, the effect of wind-driven rain is confirmed by the results of the evaluation of the level of moisture in a cellular concrete board constituting the main layer of an external wall of a heated utility building. The results were obtained both in a calculation experiment and a physical test. The selected building is located in the northern part of the town of Brest (Belarus), and the board under study is found on the south-western side of the building, so it is exposed to the most intense influence of wind-driven rain.

\section{Calculation experiment and its results}

In order to calculate non-stationary temperature and moisture fields resulting from environmental influence in the cellular concrete board under concern (whose cross-section geometric characteristics are presented in Fig.1, the authors of the present paper used their own software called THSS (Temperature Humidity Stress Strain). The mathematical description of non-stationary heat and moisture transfer processes, applied in this programme, is basically identical to the one used in the widely-known WUFI software. The differences between the latter application and the THSS are as follows: in THSS, the moisture diffusion coefficient $D_{w}\left(\mathrm{~m}^{2} / \mathrm{s}\right)$, dependent on the moisture content $\mathrm{w}\left(\mathrm{kg} / \mathrm{m}^{3}\right)$, is determined on the basis of the original method [11], and the weight of rain absorbed by one surface area unit of the shielding structure under concern during one time unit of exposure to wind-driven rain, $g_{w}\left(\mathrm{~kg} /\left(\mathrm{m}^{2} \mathrm{~s}\right)\right)$, is evaluated using the original method [11]. Finally, the influence of sun radiation is assessed with the methodology presented in [12].

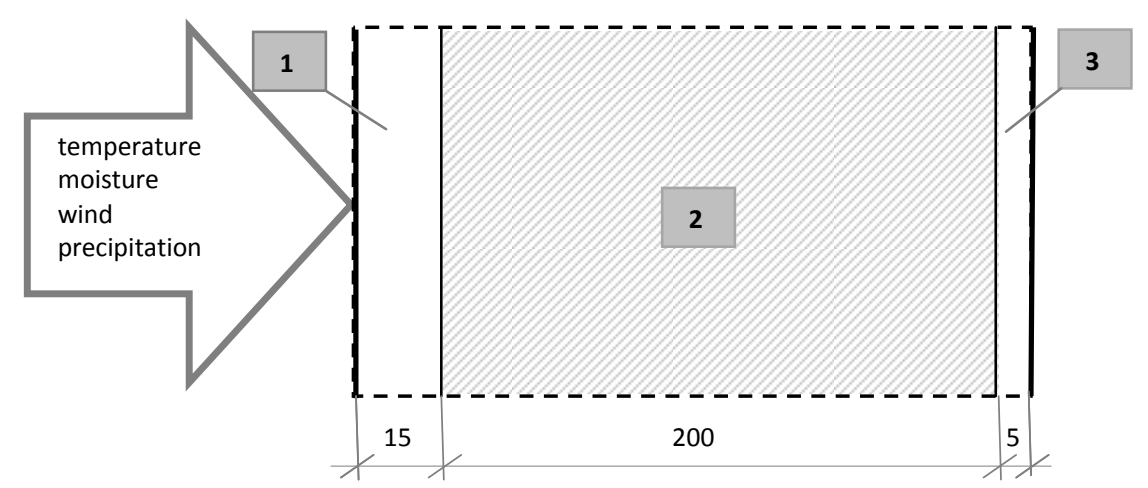

Fig.1. Cross-section of the external wall exposed to the climatic influence, 1 and 3 -cement and lime wall plaster, 2 - cellular concrete.

It was previously established that the results from the application of THSS software predicted the results obtained in physical tests of the moisture level in cement and lime mortar samples during an isothermal drying process [13], in sandstone samples for the specified climatic conditions (Alsabry et al. [7]), in cereal grain in isothermal moisture transfer [14], and in other materials quite well. This allowed the authors to assume that if the influence of the surrounding environment and of the physical characteristics of materials are taken into account accurately enough, it will be possible to obtain reliable information on the variable in time moisture levels of the external wall under study.

The calculations were provided to determine the influence of the environment (i.e., temperature, relative air humidity and precipitation in the form of rain) on the tested wall. As the sources of information on the values of the above factors are variable in time, data presented in [15] and [16] was used. The methods of collecting, archiving and processing discrete data on the environmental conditions are described 
in [17]. The discrete data were converted into continuous data using third-degree spline functions. The adopted calculation year started on 1 July and ended on 30 June. The climatic changes (temperature, relative air humidity and amount of rainfall) occurring during this calculation year are shown in Fig.2.
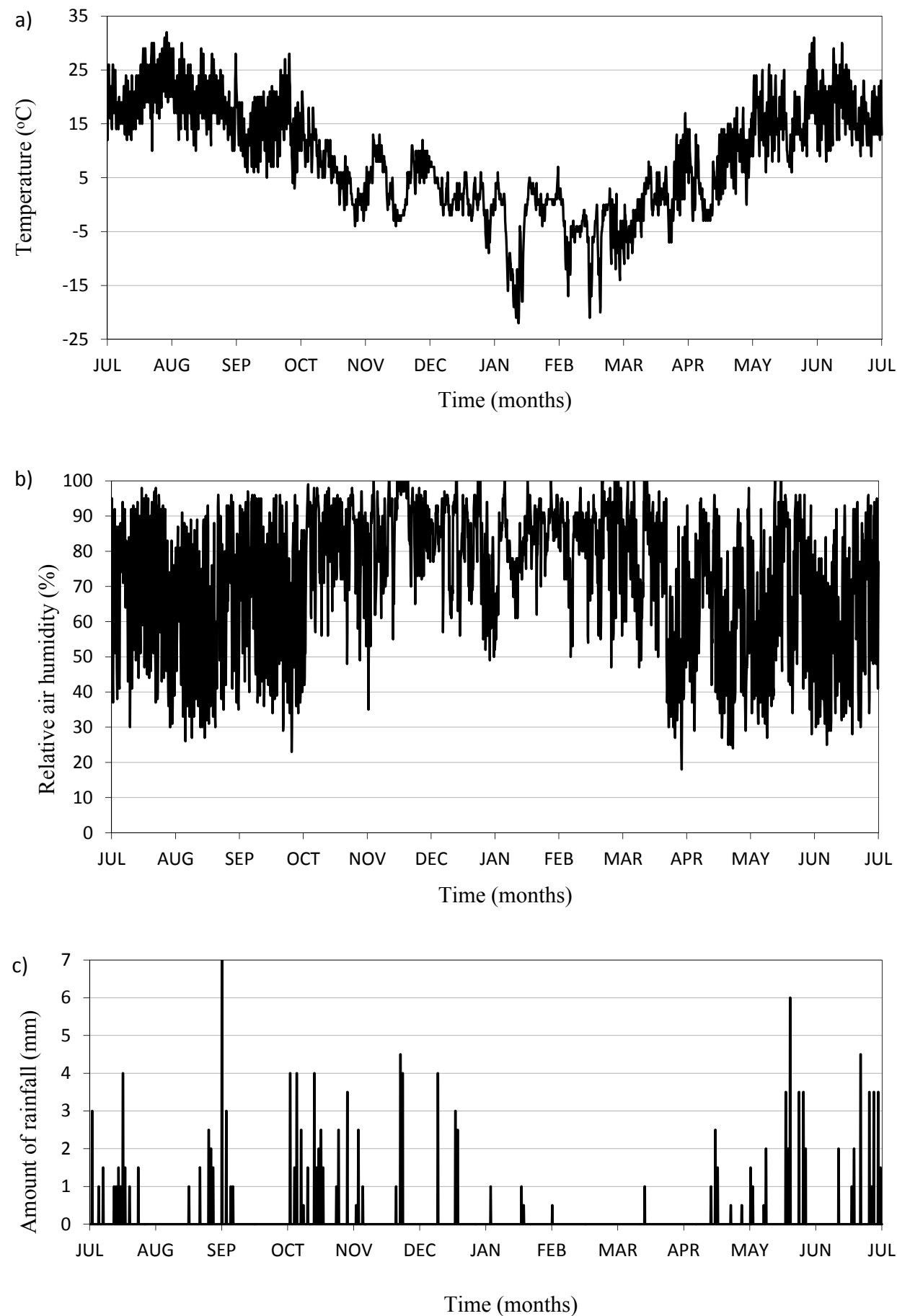

Fig.2. Changes in climatic conditions during the calculation year: a) temperature, b) relative air humidity, c) amount of rainfall.

The values describing the characteristics of cement and lime mortar of the bulk density of $\rho=1800$ $\mathrm{kg} / \mathrm{m}^{3}$ (external layer), and these describing the characteristics of cellular concrete of the bulk density of 
$\rho=1000 \mathrm{~kg} / \mathrm{m}^{3}$ (internal layer), required in order to perform the calculations, were obtained through generalising the results presented in [18], [19] and [20], and are listed in Tab.1, where $u$ stands for the weight of moisture per mass unit of the material (\%). The value of the water sorption coefficient A for cellular concrete was determined from the authors' own experiment described in the next section of the present paper. Sorption isotherms for the examined materials are shown in Fig.3. The heat transfer coefficient and the moisture exchange resistance coefficient for the external layer of the wall are $\alpha_{e}=23 \mathrm{~W} /\left(\mathrm{m}^{2} \mathrm{~K}\right)$ and $\mathrm{R}_{\mathrm{e}}=13.3$ $m^{2} \mathrm{hPa} / \mathrm{g}$, respectively, while the values of these coefficients for the internal layer are $\alpha_{i}=8.7 \mathrm{~W} /\left(\mathrm{m}^{2} \mathrm{~K}\right)$ and $R_{i}=26.6 \mathrm{~m}^{2} \mathrm{hPa} / \mathrm{g}$. The temperature and the relative air humidity of the internal layer of the examined wall during the heat supply period that started at the end of October and finished at the end of March were considered to be constant values equal to $t_{i}=18^{\circ} \mathrm{C}$ and $\Phi=55 \%$, respectively. The values of these parameters were also constant for the remaining period of the year (i.e., from 1 April to 30 October), namely $t_{i}=20^{\circ} C$ and $\Phi=70 \%$. Taking into consideration the physical test result, the initial moisture content in the cellular concrete layer was adopted at the constant level of $u=20 \%$.

Table.1. Characteristics of materials used in the wall barrier under study.

\begin{tabular}{llll}
\hline Indicators & \multicolumn{1}{c}{$\begin{array}{c}\text { Unit of } \\
\text { measurement }\end{array}$} & $\begin{array}{c}\text { Cement and lime } \\
\text { mortar }\end{array}$ & Cellular concrete \\
\hline$\lambda$ - thermal conductivity & $W /(\mathrm{m} \cdot \mathrm{K})$ & $0.8+0.064 \mathrm{u}$ & $0.14+0.01 \mathrm{u}$ \\
coefficient & $\mathrm{kJ}(\mathrm{kg} \cdot \mathrm{K})$ & $0.85+0.042 \mathrm{u}$ & $0.85+0.042 \mathrm{u}$ \\
$\mathrm{c}$ - specific heat & $\mathrm{kg} /(\mathrm{m} \cdot \mathrm{s} \cdot \mathrm{Pa})$ & $1.5 \cdot 10^{-9}$ & $2.8 \cdot 10^{-9}$ \\
$\delta_{p}$ - moisture vapour & $\mathrm{kg} /\left(\mathrm{m}^{2} \cdot \mathrm{s}^{0,5}\right)$ & 0.03 & 0.1 \\
transmission rate & & & \\
$A$ - water sorption coefficient & &
\end{tabular}

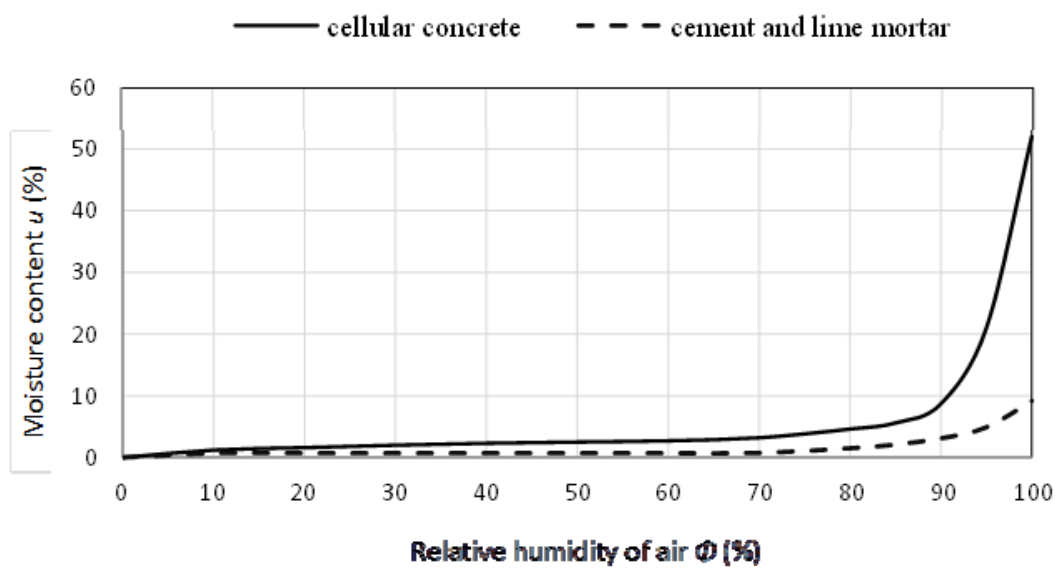

Fig.3. Sorption isotherms for cellular concrete and for cement and lime mortar.

Since the adopted initial moisture in the cellular concrete layer of the shielding structure was unquestionably different from the actual moisture distribution, annual calculations for the adopted climatic conditions were continued for two more years. In order to explain the influence of rainfall on the mean moisture content of the cellular concrete layer of the board under concern, two calculations with the use of the THSS software were made. The first calculation considered all the types of the environmental influence presented in Fig.2, i.e., including wind-driven rain. It has to be underlined at this point that the conversion from the amount of rainfall (mm) (see Fig.2c) to the weight of the rain moisture absorbed by one surface area unit of the shielding structure during one time unit of exposure to wind-driven rain, $g_{w}\left(\mathrm{~kg} / \mathrm{m}^{2} \mathrm{~s}\right)$, was performed according to the method described in [21]. In the second calculation, the influence of rainfall was not taken into account. The results of both calculations are shown in Fig.4. 


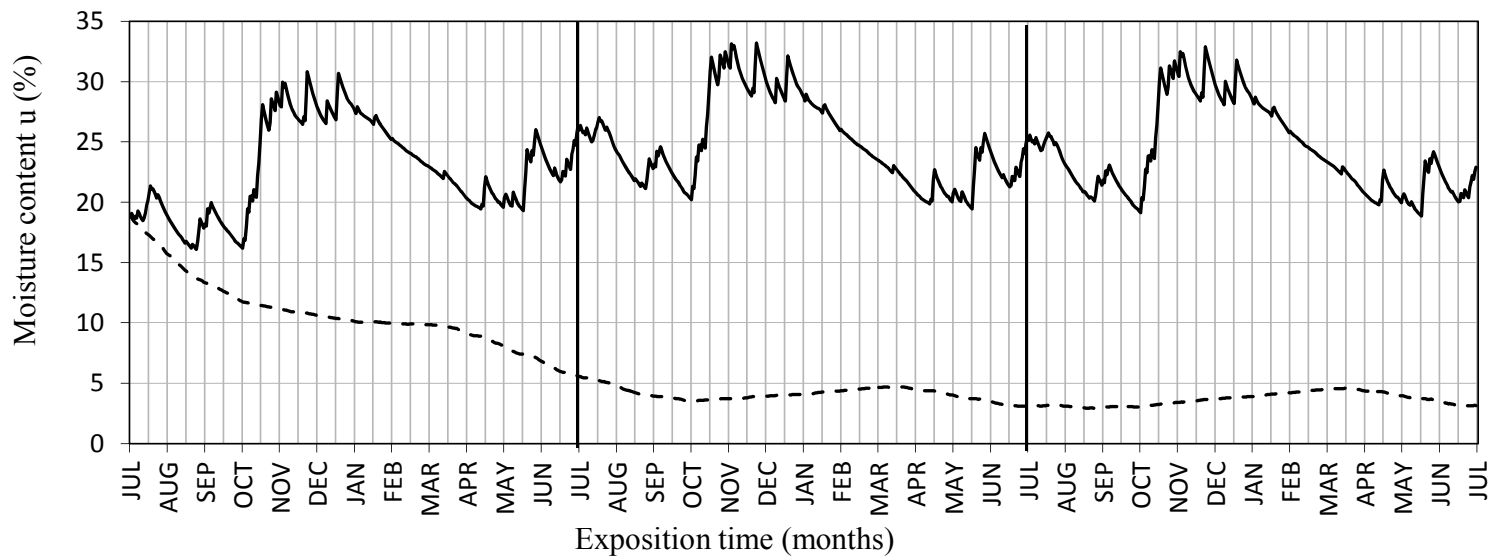

Fig.4. Changes in the mean moisture content of the cellular concrete layer of the eternal wall during three calculation years.

As can be seen from the results of the first calculation, presented in Fig.4, while comparing the annual climatic influence, changes in the values of moisture content of the cellular concrete layer for the particular years are repeated starting from the second calculation year, with the mean moisture content during the second and third calculation years changing approximately from $18 \%$ to $33 \%$, and in the first calculation year from $16 \%$ to $31 \%$. It is easy to notice that a repetition might have been observed also during the first calculation year provided that the initial mean moisture content for concrete had been assumed at the level of $25 \%$.

The presented values of the mean moisture content for cellular concrete much exceed the standard value assumed for structures in use, i.e., 4.5\%. According to the sorption isotherm shown in Fig.2, for the relative air humidity of $\Phi=80 \%$ the equivalent cellular concrete moisture is $4.8 \%$.

The calculation carried out using the THSS software (without taking into account the influence of rainfall) shows that after the end of the first year the mean moisture of the cellular concrete layer was reduced to the standard value and then it ranged approximately from 3 to $5 \%$. A similar situation was observed when performing calculations with the use of traditional standard engineering methods. In this way, the calculation experiment demonstrated that if wind-driven rain is provided for, the mean moisture of cellular concrete considerably exceeds the values calculated without taking rainfall into consideration.

\section{Physical test and its results}

In order to check whether the THSS software is capable of predicting the actual moisture distribution of the selected wall accurately enough, a physical test in real conditions was made. The samples of cellular concrete, used in the test, had been prepared by cutting holes in the selected wall board with the use of a special drill bit, and 4 cylindrical samples of $d=45 \mathrm{~mm}$ in diameter and $h=50 \pm 2 \mathrm{~mm}$ in height were taken from each hole. Thus, the cellular concrete board of $200 \mathrm{~mm}$ in thickness was divided into 4 layers of approx. $50 \mathrm{~mm}$ in thickness, labelled $i(i=1,2,3,4)$, where $i=1$ was assigned to the layer located at the most external side of the wall. The sample-taking process was performed within 24 hours: on 27 December of the first calculation year, samples were taken from the holes labelled A, B, and C (the first series of 12 samples), while on 11 September of the second calculation year, samples were taken from the holes labelled D, E, F (the second series of 12 samples). Figure 5 presents a diagram showing the location of the holes on the board surface.

The total number of samples used in the test was 24. After being taken from the hole, each sample was immediately isolated from the external environment by means of a separate polyethylene bag to prevent moisture evaporation. The $m_{w}$ weights of the damp samples were measured on the days they were taken in laboratory conditions (with the use of an electronic scales with the accuracy of $0.01 \mathrm{~g}$ ). The samples were 
then dried in a laboratory dryer at the temperature of $105^{\circ} \mathrm{C}$ until the $m_{s}$ constant weight was achieved. Next, the moisture content of the samples was calculated

$$
u=\frac{m_{w}-m_{s}}{m_{s}} 100 \%
$$

It was found that the bulk density of the dry samples ranged from $891 \mathrm{~kg} / \mathrm{m}^{3}$ to $1009 \mathrm{~kg} / \mathrm{m}^{3}$, with the mean value of $\rho=1009 \mathrm{~kg} / \mathrm{m}^{3}$. As it was mentioned before, $\rho=1000 \mathrm{~kg} / \mathrm{m}^{3}$ was adopted in the calculation experiment.

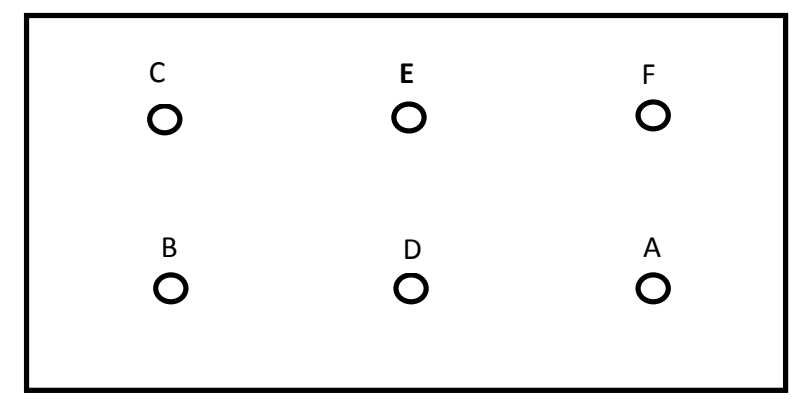

Fig.5. Location of the holes on the surface of the examined board measuring $300 \times 140 \mathrm{~cm}$.
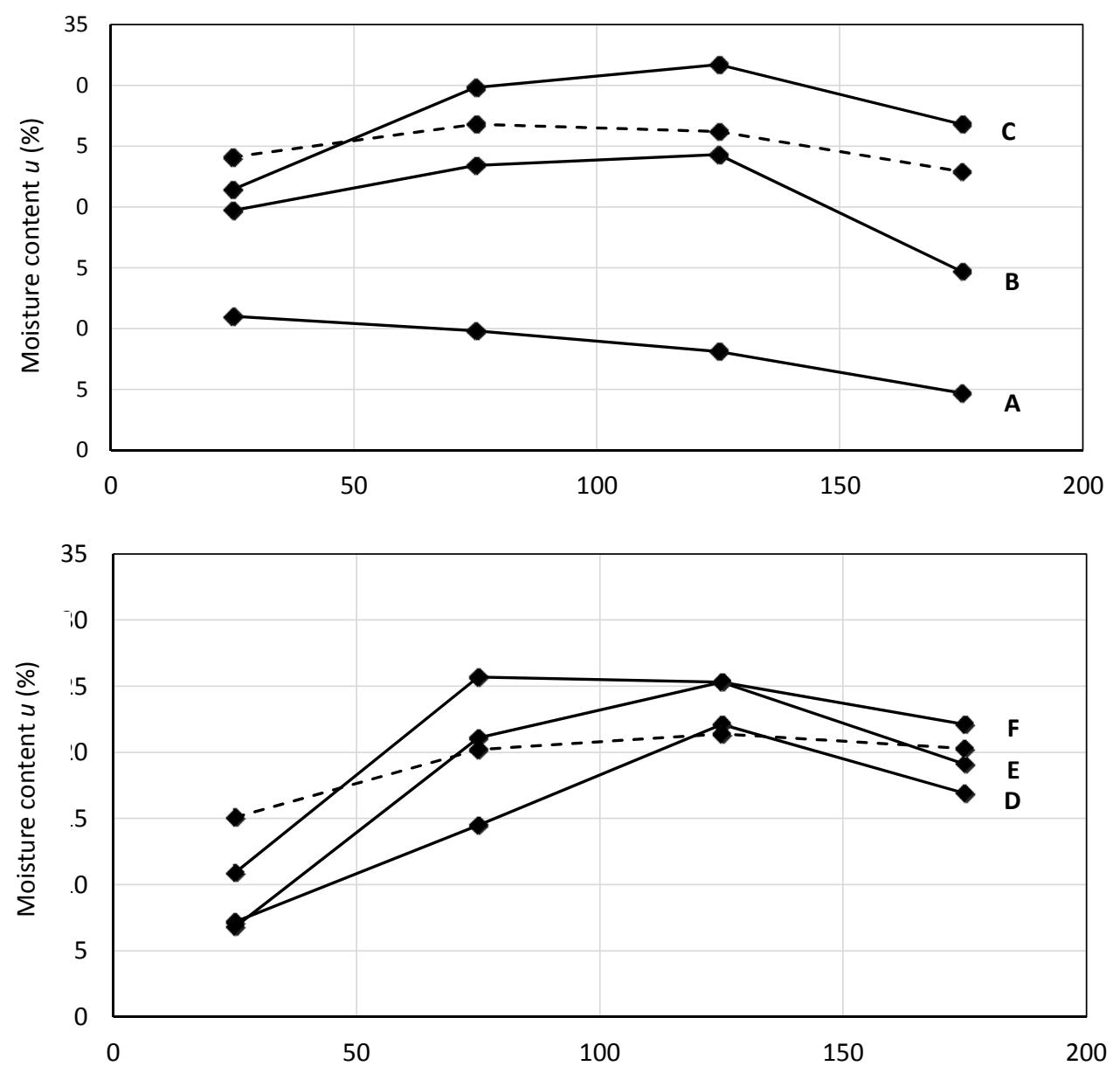

Fig.6. Mean moisture content values for cellular concrete in $50 \mathrm{~mm}$-layers along the board thickness, obtained from the physical experiment (dots connected with solid line) and from calculations (dots connected with dashed line) at the measuring points: A, B,C (a) and D, E, F (b). 
The moisture measurement results for samples taken from all the holes are illustrated in Fig.6 in the form of dots connected with solid lines. These data characterise the moisture distribution along the cellular concrete layers for the particular holes (moisture profiles) on the day of the experiment. As it can be seen from this Figure, the changeability of the moisture measurement results for any $i$-th cellular concrete layer $(i$ $=1,2,3,4$ ) of $50 \mathrm{~mm}$ in thickness during the heat supply period (see Fig.6a) was much greater than that in the remaining period (see Fig.6b).

Both qualitative and quantitative differences between the moisture profiles obtained on the basis of the moisture content values for samples from the A hole (Fig.6a) and the moisture profiles for the B and C holes were observed. This can be explained by the fact that a stationary heating device causing intensive local drying of the shielding structure material was located near the A hole during the heat supply period. As such a situation was not typical for the $\mathrm{B}$ or $\mathrm{C}$ holes located further away from the $\mathrm{A}$ hole, the moisture data concerning the 4 cellular concrete samples from the A hole were not included in the subsequent statistical analysis.

Figure 6 also shows the moisture values for cellular concrete, obtained from calculations (averaged for 4 sections of $50 \mathrm{~mm}$ each) and connected with a dashed line. The results of the calculation and of physical tests were compared on the basis of a statistical analysis of the experimental data characterised with the arithmetic mean $\bar{u}_{i}$ and the $s_{i}^{2}(i=1,2,3,4)$ variance determined from the $n_{i}$ trial for each $i$-th cellular concrete layer for the first and second series of tests. In the first experiment $n_{i}=2$, whereas in the second one $n_{i}=3$.

The hypothesis of dispersion uniformity in each experiment was evaluated using Cochran's $G$ criterion. It was established that for the first test series the experimental G-criterion is equal to

$$
\mathrm{G}_{\exp }=\frac{s_{i \max }^{2}}{\sum_{i=1}^{4} s_{i}^{2}}=\frac{73.2}{122.5}=0.5175 \text {. }
$$

For the level of significance $\alpha=0.05$, widely adopted for engineering tests, and for four $s_{i}^{2}$ comparable variances, each having $v=1\left(v=n_{\mathrm{i}}-1=2-1=1\right)$ degree of freedom, the critical value of the $G$ criterion is $G_{0.05 ; 4 ; 1}=0.9065$ and it exceeds the experimental value, i.e., $G_{e x p}=0.5175$. In such cases, the hypothesis of variance uniformity is accepted, and the combined variance characterizing the variability of the $u$ random value (cellular concrete moisture), evaluated on the basis of the data from the first test series, equals $s_{1}^{2}=\sum_{i=1}^{4} s_{i}^{2} / 4=30.63$ and has $v=4$ degrees of freedom.

After applying the same procedure of testing the hypothesis on variance uniformity of the $s_{i}^{2}$ values obtained on the basis of the data from the second experiment, we obtained the following inequality: $G_{\text {exp }}=0.671<G_{0.05 ; 4 ;}=0.768$. Such an inequality allows for considering the compared dispersions as being uniform. The combined dispersion value is $s_{2}^{2}=11.63$ with $v=8$ degrees of freedom.

Next, Fisher's $F$-criterion was used to evaluate the hypothesis on the uniformity of the $s_{1}^{2}$ and $s_{2}^{2}$ variances calculated on the basis of the experiment results of the first and second series. The mutual ratio of these dispersions, describing the experimental value of the $F$-criterion, is $F_{\text {exp }}=s_{1}^{2} / s_{1}^{2}=30.63 / 11.63=2.59$. The numerator in this ratio has $v_{1}=4$, while the denominator has $v_{2}=8$ degrees of freedom. For the level of significance $\alpha=0.05$, and for the $v_{1}$ and $v_{2}$ degrees of freedom, the critical value of the $F$-criterion amounts to 3.8 and it exceeds the experimental value, i.e., $F_{e x p}=2.59$. This is why the $s_{1}^{2}$ and $s_{2}^{2}$ variances can be regarded as being uniform. Then the $s^{2}$ combined dispersion value, characterising the variability of the $u$ random value on the basis of two experimental series, is calculated from the equation 


$$
s^{2}=\frac{s_{1}^{2} v_{1}+s_{2}^{2} v_{2}}{v_{1}+v_{2}}=18.09
$$

In that case the standard deviation is $s=\sqrt{s^{2}}=4.253 \%$. Now it is possible to compare the mean values of the experimental and calculated moisture content of cellular concrete in the analysed $i$-th layer. Therefore, as can be seen from Fig.6, the biggest difference in the mean values can be observed in the first layer $(i=1)$.

In the first experiment (see Fig.6a), the mean arithmetic moisture content in the first layer is $20.55 \%$, while the calculated one is $24.1 \%$. The difference between these values is $24.1-20.55=3.55 \%$ and it does not exceed the standard deviation $s=4.253 \%$, so it should not be considered as statistically significant. The values of such differences in the subsequent layers are even smaller.

In the second experiment (see Fig.6b), the biggest difference in the mean values was also observed in the first layer. For the experimental mean values of $8.3 \%$ and the computed value of $15.1 \%$, the difference is $15.1-8.3=6.8 \%$, and it does not exceed the double standard deviation $2 s=8.506 \%$. If this is the case, such a difference can be regarded as statistically insignificant. In the subsequent cases the biggest difference was obtained in the third layer $(i=3)$, and its value was only $2.9 \%$.

After that, the calculated and experimental mean moisture values for the whole cellular concrete layer were compared. In the first experiment, the mean experimental moisture value was $\bar{u}_{\text {exp }}=(20.55+26.6+28.0+20.25) / 4=23.98 \%$, and it was slightly (by $1 \%$ ) smaller than the calculated value $\bar{u}=(24.1+26.8+26.2+22.9) / 4=25 \%$.

Basing on the results of the second experiment, we obtained the experimental value $\bar{u}_{\text {exp }}=(18.3+20.43+24.3+19.37) / 4=18.1 \% \quad$ as well as the calculated value $\bar{u}=(15.1+20.2+21.4+20.3) / 4=19.25 \%$. In the second experiment, the computed value was also slightly higher than the experimental value.

The calculated values of cellular concrete moisture adequately predict the mean experimental moisture values both for the particular layers of $h=50 \mathrm{~mm}$ in thickness and also for the whole cross-section of the cellular concrete board of $200 \mathrm{~mm}$ in thickness. The mean experimental moisture values of the cellular concrete layer in the winter period $\left(\bar{u}_{\text {exp }}=23.98 \%\right)$ and in the summer period $\left(\bar{u}_{\text {exp }}=18.1 \%\right)$ exceed the standard value of $4.5 \%$ by a few times. For the winter measurements, this ratio is as high as 5.3 times and for the summer season it amounts to 4 times. If the moisture value of the cellular concrete layer of $\delta=0.2 \mathrm{~m}$ in thickness is increased from $4.5 \%$ to $23.98 \%$, then the $R=\delta / \lambda$ thermal resistance $\left(m^{2} K / W\right)$, adopted while designing the shielding structure for this layer, is reduced by $42 \%$.

As it was emphasised earlier (and then confirmed on the basis of the data concerning the experiments described previously), high moisture values in the shielding structure are connected with wind-driven rain falling on the surface of this structure and also with the capillary properties of the materials used in the structure. Capillary properties of materials are mainly characterised by the water sorption coefficient $A$ and the capillary saturation moisture content $w_{k}$, or by the active material porosity

$$
\Phi_{a}=\frac{w_{k}}{\rho_{w}}
$$

where $\rho_{w}$ is the density of the absorbed water.

The more precisely the values of these indicators are determined, the more accurate the results of the moisture content in the shielding structure will be. Consequently, the values of the $A$ indicator and of the $w_{k}$ moisture were determined experimentally for the cellular concrete under concern. To this end, 3 samples were taken at random from the 24 cylindrical samples prepared and dried to constant weight. Later, the weight of distilled water absorbed by one surface area unit of the cross-section of each sample (of $h$ in 
height) in the vertical direction, $W\left(\mathrm{~kg} / \mathrm{m}^{2}\right)$, was observed. The observed one-direction capillary rise of water, illustrated in Fig.7 for one of the samples, was similar in all the samples. The figure shows the procedure of determining the values of the $A$ and $w_{k}$ indicators, described in detail in [22] and [23]. The mean value of the sorption coefficient was found to be $A=0.1 \mathrm{~kg} /\left(\mathrm{m}^{2} \mathrm{~s}^{0.5}\right)$, while the mean capillary saturation moisture content was $w_{k}=400 \mathrm{~kg} / \mathrm{m}^{3}$. The obtained values were then used for calculations described in the second section.

Fig.7. Determining $A$ water sorption coefficient and $w_{k}$ capillary saturation moisture content for cellular concrete, based on data on kinetics of one-direction capillary absorption of water by cylindrical samples (of $h$ in height).

\section{Summary}

Using the calculation method (with the THSS software) and a physical experiment, the authors of the present paper assessed the non-stationary moisture level of a cellular concrete wall board in a heated utility building, depending on the climatic influence. It was observed that of all the types of climatic influence considered, the main reason for the high moisture levels in cellular concrete is wind-driven rain intensifying the process of free capillary moisture transfer. A comparative analysis of the results of the physical test and the calculation experiment showed that the THSS is able to predict the actual moisture levels of the shielding structure under study accurately enough when precise data concerning the thermal and physical characteristics of the materials as well as the occurring climatic influences are submitted.

\section{Nomenclature}

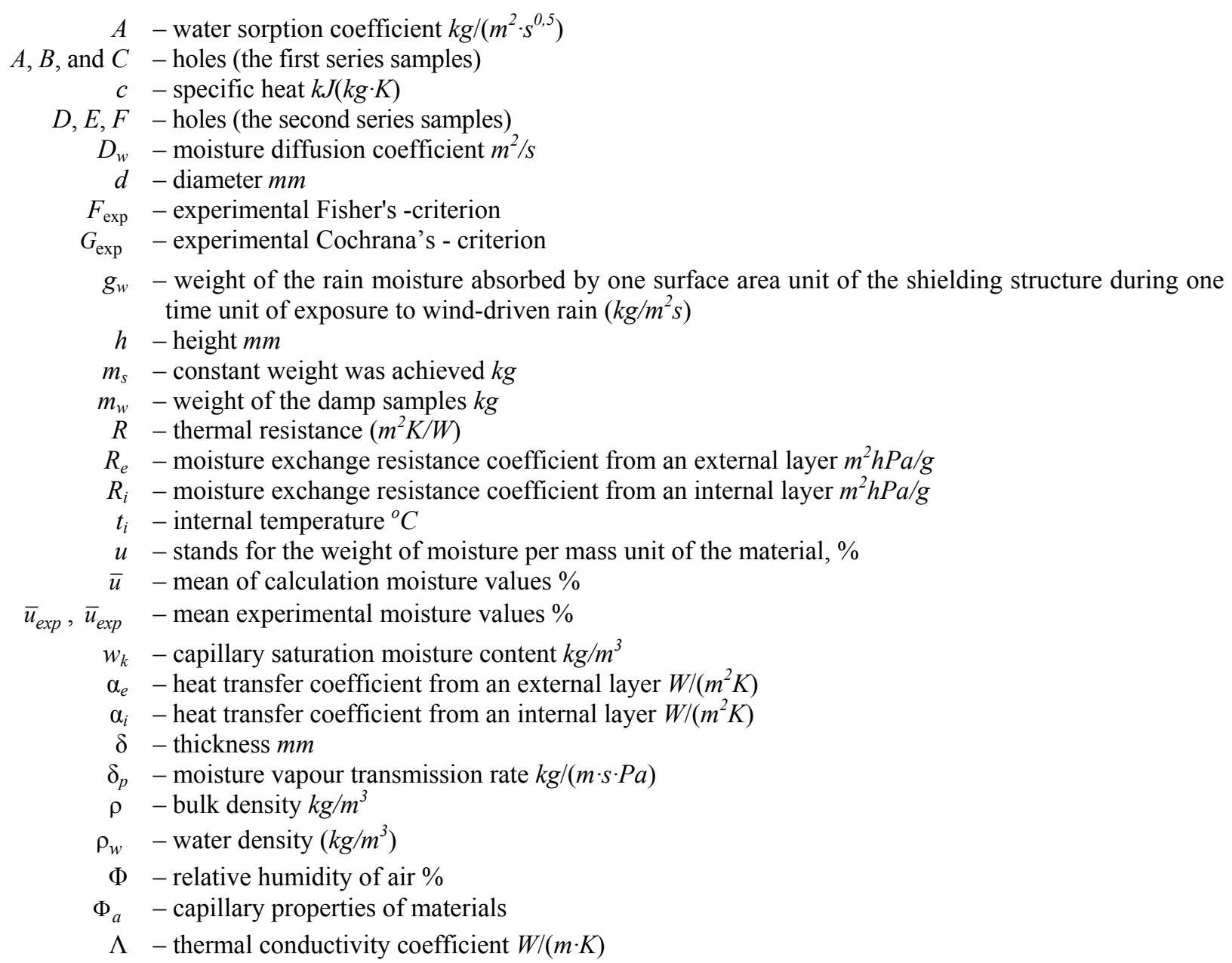




\section{References}

[1] Adl-Zarrabi B. and Högberg A.B. (2002): Microclimate: Field Measurements, Driving Rain Analyses, Building Durability - Practices. - Mat. Konf. "Performance of Exterior Envelopes of Whole Buildings VIII: Integration of Building Envelopes”, (CD), Clearwater Beach, Florida.

[2] Blocken B. and Carmeliet J. (2002): Spatial and Temporal Distribution of Driving Rain on Buildings: Numerical Simulation and Experimental Verivication. - Mat. Konf. "Performance of Exterior Envelopes of Whole Buildings VIII: Integration of Building Envelopes" (CD), Clearwater Beach, Florida.

[3] Fabien J.R. van MOOK (2002): Driving rain on building envelopes. - Eindhoven: Eindhoven University Press.

[4] Alsabry A. (2011): Moisture transport in the building envelope from capillary-porous materials. - Zielona Góra: Publishing House of the University of Zielona Góra, (in Polish).

[5] Blocken B.J. and Carmeliet J.E. (2004): A review of wind-driven rain research in building science. - Journal of Wind Engineering and Industrial Aerodynamics. N92(13), pp.1079-1130.

[6] Witczak K., Künzel H.M. and Gawin D. (2003): The influence of wind-driven rain on hygral state of building envelopes in Poland. - XLIX Scientific Conference of the Committee of Civil and Water Engineering PAS and Science Committee PZiTB „Krynica 2003”, (in Polish).

[7] Alsabry A., Nikitin V. and Kofanow V. (2006): The influence of precipitation and moisture transfer characteristics of the casing construction material on their moisture content. - Przegląd Budowlany, No.6, pp.39-42 (in Polish).

[8] Alsabry A. (2011): Incorporation of capillary properties of materials in modeling of curtain walls loaded by the wind-driven rain. - International Journal of Applied Mechanics and Engineering, vol.16, No.4, pp.1205-1213.

[9] Alsabry A. and Wilmański K. (2011): Iterative description of freezing and thawing processes in porous materials. ZAMM - Zeitschrift für Angewandte Mathematik und Mechanik, vol.91, No.9, pp.753-760.

[10] Alsabry A. (2011): The effect of the accuracy of capillary diffusion coefficient determination on moisture state of curtain walls during rainfall. - International Journal of Applied Mechanics and Engineering, vol.16, No.3, pp.637648.

[11] Nikitsin V.I. and Backiel-Brzozowska B. (2012): Methods of determination of liquid transfer coefficient in building materials. - Int. J. Heat Mass Transf., vol.55, pp.4318-4322.

[12] Pašinskij V.A., But'ko A.A., Ivaškevič P.I. and Petrovskaâ V.V. (2013): Experimental estimation of cumulative monthly direct and diffuse solar radiation impacts. - Energoeffektivnost'. N1, pp.26-29 (in Russian).

[13] Kofanov V.A. and Nikitsin V.I. (2004): Moisture and stress fields in a damp wall on isothermal drying. Construction and Architecture; 1. pp.122-125. (in Russian)

[14] Nikitsin V.I., Prusiel J.A. and Kofanov V.A. (2006): Evaluation of isothermal transport of moisture in granular material filling silos and containers. - Trailer of the Brest State Technical University. Construction and Architecture, 1, pp.100-104 (in Russian).

[15] Internet portal (electronic source) http://meteo.infospace.ru/. - access date 15.03.2014.

[16] Ŝver CA ed. Brest climate, Savikovsij IA Gidrometeoizdat; 1979 (in Russian).

[17] Kofanov V.A. (2011): Automation of the preparation of input data for computer program THSS. Contemporary problems of mathematics and technology. - Materials of the 7th National Scientific Conference of Young Scientists and Students. Thermal Physics of Curtain Walls. Brest, 26-28.11.2011. Brestskij Gosudarstvennyj tehničeskij Universitet, ed. Rubanov VC; 2011; pp.42-44 (in Russian).

[18] Künzel H.M. (1995): Simultaneous heat and moisture transport in building components. One-and two- dimensional calculation using simple parameters. - Fraunhofer Irb Verlag- Stuttgart.

[19] Fokin K.F. (1973): Building heat equipment, ecology. - Moscow: Stroizdat (in Russian).

[20] Bal'ân L.G. ed. (1984): A guide to determining moisture parameters of building curtain walls. - NIISF Gosstroâ SSSR. M.: Strojizdat; (in Russian). 
[21] Nikitsin V.I. and Backiel-Brzozowska B. (2013): On taking wind-driven rain and capillary characteristics of materials into account while calculating dampness of shielding structures for buildings, Modern materials, installations and construction technologies. - Ed by S. Fic. Publishing house PSWJPII. Biala Podlaska: pp.36-46.

[22] Janz M. (2000): Moisture transport and fixation in porous materials at high moisture levels. - Doctoral Dissertation, Report TVBM-1018, Division of Building Materials, Lund Institute of Technology, Lund University.

[23] Garbalińska H. (2002): Isothermal coefficients of moisture transport of porous building material. - Scientific Works of Szczecin University of Technology (in Polish).

Received: March 13, 2017

Revised: June 23, 2017 